\title{
Work Alienation as a Mediator of the Relationship of Procedural Injustice to Job Stress
}

Adnan Ceylan, Seyfettin Sulu*

Abstract:

Procedural justice, which refers to the perceived fairness of decision-making procedures, is accepted as an important antecedent of several job attitudes and behaviors such as turnover intention, organizational commitment, trust, and stress in organizational justice literature.

This study examined the relationship of procedural injustice to job stress, and whether work alienation, which has not been referred to in justice literature before, serves as a mediator in this relationship. Two dimensions of work alienation (powerlessness and social isolation) were addressed for this study. It was hypothesized that procedural injustice causes job stress, and work alienation serves as a mediator in this relationship. These relationships were tested in a sample of 383 health care professionals (doctors and nurses) from public and private hospitals in Istanbul. The results revealed that procedural injustice was associated with job stress and each of the work alienation dimensions partially mediated this relationship. The theoretical and practical implications of this results are discussed below.

Keywords: Procedural Injustice, Job Stress, Powerlessness, Social Isolation, Work Alienation

JEL: M10

DOI: $10.2478 / v 10033-010-0016-1$

\section{Introduction}

Researchers who have studied procedural justice claim that it affects several employee work attitudes and behaviors, such as job satisfaction, turnover intention, absenteeism, stress, organizational commitment, and trust (Dailey and Kirk 1992; Boer et al. 2002; Vermunt and Steensma 2003; Greenberg 2004; Hubbel and ChoryAssad 2005). In recent years, the health care industry has become a focus of research, especially in the context of hospital-based care. Therefore, many studies have examined the influence of organizational justice on the attitudes and behaviors of hospital employees. Among health care professionals, nurses appear to be the most discussed group by several researchers in organizational justice. Posthuma, Maertz, and Dworkin (2007) state that multiple dimensions of procedural justice were effective on the turnover behavior of nurses in the context of workscheduling. Another study showed that procedural injustice was a significant predictor of destructive behavioral intentions among maternity nurses (leaving the organization, reporting sick, coming late etc.) (VanYperen et al. 2000). Greenberg (2006) examined insomnia as a reaction to a particular work-related stressor among 467 nurses working at 4 hospitals. He found that a change in pay policy led workers to
* Adnan Ceylan
Department of Business Administration Gebze Institute of High Technology (GYTE), Turkey
E-mail: aceylan@gyte.edu.tr
Seyfettin Sulu
Department of Business Administration Gebze Institute of High Technology (GYTE), Turkey
E-mail: seyfettinsulu@hotmail.com 
experience stress, and that insomnia was significantly greater among nurses whose pay was reduced. In Leiter and Maslach's (2009) study, workload, control, reward, community, fairness, and values were defined as the six key areas of worklife predictive of burnout which they defined as a prolonged response to chronic interpersonal stressors on the job.

Research on work alienation has also focused on its nature and predicting its antedecents and consequences, such as isolation in organizations, organizational leadership, organizational citizenship behavior, organizational commitment, work experience and drinking behavior (Miller 1975; Sarros et al. 2002; Banai and Reisel 2007; Mendoza and Lara 2007; Banai, Reisel, and Probst 2004; Yang, Yang, and Kawachi 2001). However, no study could be found that referred to the relationship between procedural justice and work alienation.

This study takes into account the perceived procedural injustice of health care professionals, and examines whether it has an effect on job stress, and whether work alienation mediates this relationship. Health care professionals were chosen for this study for several reasons. First, health care is one of Turkey's most important industries, and has been rapidly growing in recent years. This rapid growth has brought several complaints, especially as work outcomes (pay, bonus etc.) have begun to rise among health care professionals. Second, procedural justice may be an effective organizational justice dimension to prevent these complaints. Third, procedural injustice leads to lack of control, and may cause escapist coping (e.g. turnover) to alter this source of stress. Consequently, losing these highly technically skilled health care professionals may prove costly for a hospital.

\section{Literature Review}

\subsection{Procedural Injustice}

Individuals are not only interested in the outcomes they receive in organizations but also consider the allocation processes (decisions) important as well. The judgment process related to allocation decisions is termed procedural justice (Krehbiel and Cropanzano 2000). Procedural justice refers to how an allocation decision is made (Konovsky 2000). It is the perceived fairness of procedures which are the means used to determine outcomes (Greenberg 1990; Konovsky 2000;
Folger and Konovsky 1989; Ambrose, Seabright, and Schminke 2002; Lam, Shaubroeck, and Aryee 2002; Robbins, Summers, and Miller 2000). Any violation by a decision-maker or an organization can arouse perceptions of procedural injustice (Kickul, Gundry, and Posig 2005). According to the control model, procedural justice provides employees with indirect influence over the outcome of the decision-making process by means of process control. Process control, which has also been called voice in justice literature, refers to an employee's possibility to express his/her views during the decisionmaking process (Elovainio et al. 2004). Procedural justice contains the structural features of a decision making process, such as the amount of employee voice (Cropanzano, Prehar, and Chen 2002). Employees prefer procedures which allow them to control input into decision-making processes to gain favorable or desired personal outcomes (Konovsky 2000). When procedures give them the opportunity of control they perceive the processes and decisions as more fair (Elovainio et al. 2004; Alder and Ambrose 2005).

Decision-making procedures allow voice and help employees to control and influence material outcomes (Konovsky 2000; Price et al. 2006). Such control can produce more favorable outcomes (Greenberg 1990). If a distribution of outcomes or a process satisfies certain criteria, employees believe that it is fair, and consequently, that these fair procedures lead to fair distributions (Boer et al. 2002; Hegtvedt, Clay-Warner, and Johnson 2003). Fair processes facilitate the acceptance of outcomes even when these are undesirable (Greenberg 2001). Furthermore, fair treatment reduces some of the uncertainty experienced in working life, and helps employees to predict and control future events more easily (Colquitt et al. 2006). Before a decision is made the concerns of all affected subgroups and individuals should be considered carefully (Kickul, Gundry, and Posig 2005; Schmitt and Dörfel 1999). Allocation processes and procedures should be representative of all affected employees' views, opinions, needs, and values in the process (Judge and Colquitt 2004; Cohen-Charash and Spector 2001). Posthuma, Maertz, and Dworkin (2007) stated that the information used in a decision by management should fairly represent the views of all affected employees. The procedure must guarantee that all affected parties have an opportunity to state their views and concerns (Nowakowski and Conlon 2005).

Another explanation is offered in the group value model that voice increases feelings of inclusion, respect, 
and standing within a group (Price et al. 2006). The group value model examines procedures in terms of their relational aspect. Fair procedures construct employees identities based on the group to which they belong. Fairness in a group communicates to employees that the group values them (Blader and Tyler 2003). Being treated by important group members in a fair manner leads to positive feelings such as feeling respected and being proud to be a member of the group (Elovainio et al. 2005).

\subsection{Job Stress}

Stress is a result of adverse work experiences such as uncertainty or lack of control. These work experiences that cause stress are often referred to as stressors (Judge and Colquitt 2004). Organizational injustice is a type of job stressor which affects psychological, physical, and behavioral reactions (Elovainio et al. 2004). When people are treated unfairly they may experience stress. For example, when an employee discovers that a new employee is being paid more than him/her this situation may cause him/her to experience stress (Greenberg 2004). Employees accept procedural injustice as a stressor, which produces psychological distress (Tepper 2001). Unfair outcomes will be accepted as more fair when allocation procedures are seen as fair. Allowing voice in a decision making process related to allocations increases employees' perceived fairness of the outcome decision, and decreases stress (Vermunt and Steensma 2003).

In a stressful work environment excessive demands are made of the individual. The individual lacks the abilities or is not fully equipped to cope with a stressful situation (Jamal 2005). Uncertainty and lack of control form the basis of the stress construct, and procedural justice allows for long-term outcomes to be controlled and predicted more easily (Judge and Colquitt 2004). As a result of an unfair procedure, an employee may likely think that he/she is unable to predict and control future events and in turn, experiences stress. According to Elovainio et al. (2005) control refers to having power or mastery in an environment and may reduce stress situations. To be able to control a potentially threatening situation helps individuals to predict the result and reduce uncertainty.

Perceived procedural injustice will cause employees to think that they lack the opportunity to control decision making procedures. Consequently, this lack of control and uncertainty related with the result of decision making procedures will cause employees to experience stress.

\subsection{Work Alienation}

When an employee is not able to express him/ herself at work due to a loss of control over the product and process of his or her labor, work alienation occurs (Mendoza and Lara 2007). As a result of the absence of autonomy and control in the workplace, workers may experience alienation. If the work environment cannot satisfy the needs of individual autonomy, responsibility, and achievement of the workers, it will create a state of alienation (Kanungo 1983). When a person is treated exclusively, differently or unfairly because of his or her group membership he or she often feels alienated and angry (Enshner, Grant-Vallone, and Donaldson 2001). Organizations in which there is a lack of autonomy for employees in the selection of tasks and that do not allow enough participation in decision making are likely to cause a high degree of work alienation. There iss an inverse relationship between alienation from work and participation in decision making. In one case of low participation in decision making, trainees from a management training program experienced work alienation (Allen and LaFollette 1977).

Alienation at the workplace means that employees may not be able to fulfill their social needs (Nasurdin, Ramayah, and Kumaresan 2005). Alienation decreases the motivation of workers, psychologically separates them from work and acts to reduce work involvement. Alienated workers are unable to satisfy their salient needs and expectations from work (Banai, Reisel, and Probst 2004) and form a gap between perceptions of an objective work situation and their personal interests such as values, ideals, and desires (Mendoza and Lara 2007). They view their jobs instrumentally, avoid autonomy, responsibility, and higher status, and engage in nonwork pursuits. They do not care personally for participation in work processes - their goal is solely to earn money (Shepard 1970).

As can be seen, these expressions of discontent are similar to those of the control model and the group value model. If employees are treated unfairly within group relations or deprived of voice in processes they are likely to experience alienation. We proposed that two dimensions of work alienation (powerlessness and social isolation) are related to organizational justice, and examined this relationship in this study. 
Powerlessness is the absence of control over events in a person's life (Banai and Reisel 2007) and the inability for employees to control their work processes at the workplace (Yang, Yang, and Kawachi 2001; Bacharach and Aiken 1979). In an alienated work environment, workers neither control the work process nor participate in organizational decision-making. Generally, powerlessness may have two sub-dimensions: whether the workers are free of action in the work process, or have influence on organizational decision-making (Bacharach and Aiken 1979). The sense of powerlessness is a stable individual response to the various social contexts a person is involved in (Heinz 1991). Alienated workers perceive that control is lacking over the pace and method of the work and over his or her physical movements (Leiter 1985). Lack of freedom or autonomy leads to powerlessness (Ambrose, Seabright, and Schminke 2002), leaving employees unable to exert control over work activities, and as a result suffer a lack of job autonomy (Mendoza and Lara 2007).

According to the cognitive appraisal Model, when someone has been harmed by an event (for example, an unfair disbribution), he/she assesses whether he/she can avoid or minimize the harm. Not to be able to deflect the harm may cause feelings of powerlessness (Greenberg 2004). People who are not allowed voice and/or decision control may perceive future harm/loss as a threat and experience psychological distress (Tepper 2001). Low procedural justice may cause employees to perceive little or no control, and this sense of powerlessness can prevent him/her from taking action against the source of stress (Zellars et al. 2004).

Powerlessness means that one has no influence on decisions. Nursing discourse was subordinated to managerial discourse, and nurses were relatively powerless in relation to managers. The behavior of managers influenced this powerlessness, and this powerlessness had a mediating effect between the behavior of managers and stress (Taylor, White, and Muncer 1999). Nurses tend to avoid feelings of powerlessness because powerlessness prevents them from solving problems. Status and power help nurses to resolve or ignore conflicts with doctors (Tabak and Koprak 2007).

A socially isolated employee is not supported or helped by his or her colleagues or superiors (Yang, Yang, and Kawachi 2001). These employees do not have enough inclusion and social acceptance at the workplace (Banai and Reisel 2007) and perceive that they have a lack of integration with their coworkers, their occupation, or the organization where they work (Leiter 1985). Organizations do not equally distribute personal influence or organizational power, and do not generate equally flexible or identically rewarding interaction patterns among their members. The amount of freedom workers have to socially interact with other members affects their ability to influence the group's functioning (Miller 1975).

According to the group value model of justice an unfair procedure indicates that an individual is a low status member within the group or the relationship between group member and the authority figure is negative (Cropanzano et al. 2001). Implementation of unfair procedures, or to not apply procedures fairly and/or to exclude employees from decision making procedures may likely cause them to feel isolated. Furthermore, allocation processes and procedures which are not representative of the affected employees' views, opinions, needs, and values may likely cause feelings of isolation.

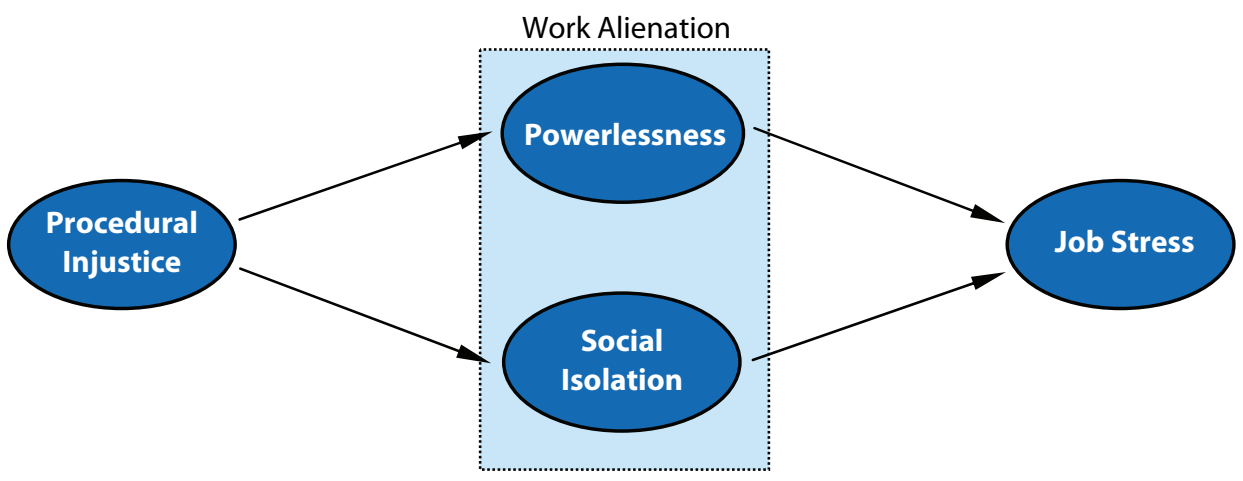

Figure 1: Proposed Model 


\section{Research Model and Hypotheses}

In the light of these explanations, we expect that a relationship exists between perceived procedural injustice and job stress. In addition, we propose that two dimensions of work alienation (powerlessness and social isolation) have mediating roles in the relationship between procedural injustice and job stress. We present the hypotheses and proposed model below.

Hypothesis 1: Employees' perceptions of procedural injustice will be positively associated with their sense of work alienation. Specifically, employees' perceptions of procedural injustice will be associated with their sense of (a) powerlessness, and (b) social isolation.

Hypothesis 2: Employees' perceptions of procedural injustice will be positively associated with job stress.

Hypothesis 3: Work alienation will mediate the relationship between perceived procedural injustice and job stress. Specifically, (a) powerlessness and (b) social isolation will mediate the relationship between perceived procedural injustice and job stress.

\section{Methodology}

\subsection{Procedure and Participants}

Questionnaires were created on the basis of scales obtained from relevant literature, and were distributed to 700 doctors and nurses working in public and private hospitals in Istanbul via electronic mail and face to face interviews. Of the 700 distributed, 413 questionnaires were returned. Thirty questionnaires were excluded from the analysis because of missing or incorrect marking. In the end, 383 valid questionnaires were analyzed. Of the respondents, 66.8 percent were from public hospitals, and 33.2 percent were from private hospitals. In terms of profession, 69.8 percent of the sample consisted of doctors with the remaining 30.2 percent nurses.

\subsection{Measures}

All construct items were assessed using a five-point Likert-type scale ranging from $1=$ strongly disagree, and $5=$ strongly agree.

Procedural injustice was assessed with a 8-item scale which referred to the procedures used to arrive at outcomes. Sample items included "I am not able to express my views and feelings during those procedures". Colquitt's (2001) original scale items were converted to negative statements in order to measure the degree of perceived injustice.

Work Alienation was measured by a total of 15 -items from two distinct studies. Six items from Leiter (1985) and nine items used by Yang et al. (2001) were adopted by this study. Of the total 15 items, 4 items were removed from the scale due to the low factor loadings. The work alienation scale included the dimensions of Powerlessness and Social Isolation. Powerlessness was measured by 4 items. Sample items included "I am not allowed to express my own opinions and views on the job". The measure of social isolation included 7 items. Sample items included "I am not able to get practical help from colleagues when difficulties are encountered".

Job Stress was measued by a 5 -item scale adopted from House and Rizzo (1972). Sample items included "If I had a different job, my health would probably improve".

\section{Results}

We conducted the principal components analysis with a varimax rotation to investigate whether the variables were distinct constructs. In order to conclude whether the amount of data was sufficient to measure our research and adequate for the factor analysis, both a "KaiserMeyer-Olkin (KMO) test" and "Bartlett's Test of Sphericity" were conducted. To be able to perform a factor analysis, to a certain extent there must be correlation between variables. If the result of the Barlett's test is lower than .05, there is sufficient relationship between variables to conduct a factor analysis. The KMO measure of sampling adequacy varies between 0 and 1 , the minimum acceptable level is .50, and the result is considered better as this value approaches 1 (Sipahi, Yurtkoru, and Cinko 2008).

The results of Barlett's test of our study was .000 (significant at the level of $\mathrm{p}<.001$ ), and the KMO result was .92 for the study's variables. Therefore, the result of this test indicated that our scale was sufficient to measure the variables. As expected, each of the study variables (procedural injustice, powerlessness, social isolation, and job stress) were loaded onto separate factors. Total variance was explained at .66 percent. Table 1 shows descriptive statistics, reliabilities, and pearson correlations for all variables. Croanbach alpha reliabilities for all scales shown on the diagonal in parantheses were above .70, 


\begin{tabular}{lcccccc}
\hline & Mean & SD & $\mathbf{1}$ & $\mathbf{2}$ & $\mathbf{3}$ & $\mathbf{4}$ \\
\hline 1. Procedural Injustice & 3.29 & 1 & $(.92)$ & & & \\
2. Powerlessness & 2.64 & .94 & $.480^{* *}$ & $(.85)$ & & \\
3. Social Isolation & 2.72 & .92 & $.472^{* *}$ & $.542^{* *}$ & $(.90)$ & \\
4. Job Stress & 3.17 & .98 & $.418^{* *}$ & $.488^{* *}$ & $.481^{* *}$ & $(.85)$ \\
\hline
\end{tabular}

** $p<.01$, All significance tests are two-tailed.

Croanbach alpha reliabilities for all scales shown on the diagonal in parantheses

Table 1. Descriptive Statistics, Reliabilities, and Pearson Correlations $(\mathrm{N}=383)$

\begin{tabular}{|c|c|c|c|c|c|c|c|c|c|}
\hline \multirow[b]{2}{*}{ Variable } & \multicolumn{3}{|c|}{ Powerlessness } & \multicolumn{3}{|c|}{ Social Isolation } & \multicolumn{3}{|c|}{ Job Stress } \\
\hline & $\boldsymbol{\beta}$ & $t$ & $p$ & $\boldsymbol{\beta}$ & $t$ & $p$ & $\boldsymbol{\beta}$ & $t$ & $p$ \\
\hline \multirow[t]{4}{*}{ Procedural Injustice } & $.48^{* * *}$ & 10.70 & .000 & $.47^{* * *}$ & 10.44 & .000 & $.42^{* * *}$ & 8.98 & .000 \\
\hline & \multicolumn{3}{|c|}{ R 0.48} & \multicolumn{3}{|c|}{0.47} & \multicolumn{3}{|c|}{ R 0.42} \\
\hline & \multicolumn{3}{|c|}{$R^{2} \quad 0.23$} & \multicolumn{3}{|c|}{$R^{2} \quad 0.22$} & $R^{2}$ & \multicolumn{2}{|l|}{0.18} \\
\hline & \multicolumn{3}{|c|}{$\boldsymbol{F} 114.32^{* * *}$} & \multicolumn{3}{|c|}{ F $109.07^{* * *}$} & \multicolumn{3}{|c|}{$\boldsymbol{F} 80.60^{* * *}$} \\
\hline
\end{tabular}

$p<.001$, All significance tests are two-tailed

Table 2. Regression Results for Hypotheses 1 and 2

and were acceptable levels. We have proved that the scales we used for our research were all reliable.

Having shown that the scales were reliable and sufficient to measure our data, we may move on to the correlation analysis. As shown in Table 1, procedural injustice was positively related with work alienation dimensions. Procedural injustice was significantly and positively associated with powerlessness $(r=.480)$, and social isolation $(r=.472)$ at the level of .01 . This means that the more employees' perceived procedural injustice the greater their sense of work alienation. These results show that employees' levels of perceived procedural injustice are a significant predictor of work alienation.

The relationship between procedural injustice and job stress was positively significant at the level $.01(r=.418)$. The relationships between powerlessness and job stress, and social isolation and job stress were also statistically significant ( $r=.488, r=.481$ at the level .01 , respectively).

To test Hypotheses 1 and 2, we conducted a series of regression analyses. As shown in Table 2, procedural injustice significantly predicted powerlessness $(\beta=.48, p<$ $.001)$ and social isolation $(\beta=.47, p<.001)$. Hypothesis 1 was supported. Procedural injustice was a statistically significant predictor of work alienation. In addition, procedural injustice was also predictive of job stress ( $\beta=$ $.42, \mathrm{p}<.001)$. Hypothesis 2 was also supported. Employees' perceptions of procedural injustice were positively associated with job stress. Eighteen percent of the variance in job stress was accounted for by procedural injustice.

In Hypothesis 3, it was proposed that work alienation would mediate the relationship betweeen procedural injustice and job stress. To test this relationship, a mediated regression analysis was conducted.

According to Baron and Kenny (1986) four conditions must be met for a mediation. First, the independent variable must be related to the mediator. This relationship was tested in Table 1 and 2, and found to exist. Procedural injustice affected both powerlessness and social isolation separately. Second, the independent variable must be related to the dependent variable. This result is also displayed in Tables 1 and 2. Procedural injustice was associated with job stress. For condition 3, the mediator must be related to the dependent variable. As shown in Table 1, there were relationships between each of the mediator variables (powerlessness and social isolation) and job stress. For condition 4, the previously significant relationship between the independent variable and the dependent variable must be no longer significant when the mediator is controlled. The independent variable must account for less or no variance when the mediator is included in the regression equation. If the independent variable has no significant effect after controlling for the mediator, full or perfect mediation is supported. If the effect of the independent variable is reduced but still significant when the mediator 


\begin{tabular}{|c|c|c|c|c|c|c|}
\hline \multirow[b]{3}{*}{ Variable } & \multicolumn{6}{|c|}{ Job Stress } \\
\hline & \multicolumn{3}{|c|}{ Step 1} & \multicolumn{3}{|c|}{ Step 2} \\
\hline & $\boldsymbol{\beta}$ & $t$ & $p$ & $\boldsymbol{\beta}$ & $t$ & $p$ \\
\hline Procedural Injustice & $.42^{* * *}$ & 8.98 & .000 & $.24^{* * *}$ & 4.80 & .000 \\
\hline Powerlessness & & & & $.37^{* * *}$ & 7.54 & .000 \\
\hline$R^{2}$ for each step & & .18 & & & .28 & \\
\hline$R^{2} \Delta$ & & & & & .10 & \\
\hline$F$ & & $80.60^{* * *}$ & & & $56.91^{* * *}$ & \\
\hline & $\boldsymbol{\beta}$ & $\boldsymbol{t}$ & $\boldsymbol{p}$ & $\boldsymbol{\beta}$ & $t$ & $\boldsymbol{p}$ \\
\hline Procedural Injustice & $.42^{* * *}$ & 8.98 & .000 & $.25^{* * *}$ & 4.97 & .000 \\
\hline Social Isolation & & & & $.37^{* * *}$ & 7.39 & .000 \\
\hline$R^{2}$ for each step & & .18 & & & .28 & \\
\hline$R^{2} \Delta$ & & & & & .10 & \\
\hline$F$ & & $80.60^{* * *}$ & & & $54.58^{* * *}$ & \\
\hline
\end{tabular}

Table 3. Hierarchical Regression Results for Hypothesis 3

is controlled, partial mediation is indicated. The results of mediated regression analysis are shown in Table 3.

As shown in Table 3, the previously significant relationship between procedural injustice and job stress $(\beta=.42, p<.001)$ was reduced but was still significant when the mediator (powerlessness) was entered in the regression equation $(\beta=.24, p<.001)$. This result showed that a sense of powerlessness partially mediated the relationship between procedural injustice and job stress. Hypothesis $3 a$ was partially supported. The previously significant relationship between procedural injustice and job stress was reduced but still significant when the mediator social isolation was entered in the regression equation $(\beta=.25, p<.001)$. This result showed that a sense of social isolation partially mediated the relationship between procedural injustice and job stress. Hypothesis 36 was partially supported.

\section{Discussion}

The results revealed that procedural injustice has effects on each of the work alienation dimensions and job stress. Uncertainty and lack of control are the basis of both procedural injustice and job stress. According to the control model of justice, decision-making procedures allowing employees to control (voice) the process helps them to control and influence material outcomes, to predict future events, and to obtain more favorable outcomes. If employees do not have the possibility of such control or voice they are unable to affect decisions, and hence experience job stress. The present results clearly indicate that procedural injustice is a significant predictor of job stress.

The link between procedural injustice and job stress was partially mediated by powerlessness and social isolation. Control over one's job is an important aspect of feelings of powerlessness. The powerlessness dimension of work alienation indicates similar views with the control model of procedural justice. An employee who cannot reflect his/her views and opinions on procedures, and has a lack of control over processes or decisions thinks that he/she cannot affect these processes and as a result experiences a feeling of powerlessness. In addition, an employee whose concerns, views, needs, and opinions are not considered in a decision making process feels him/herself isolated. According to the group value model, an unfair procedure indicates that the individual is a low status member within the group, and unfairness in this group leads to a sense of isolation. This sense of powerlessness and isolation ultimately lead to job stress.

The findings of this study are particularly important in organizations with professional or technical-skilled employees. Dailey and Kirk (1992) state that losing successful and highly technical skilled employees may have negative consequences for an organization. Employees with these skills are in great social and material demand. Powerlessness may have possible negative consequences in the form of several job attitudes and behaviors of employees such as increased turnover, absenteeism or destructive behaviors. Ambrose, Seabright, and Schminke (2002) state that individuals 
who have a feeling of powerlessness may engage in destructive behaviors such as sabotage to regain control. Greenberg and Barling (1999) state that job insecurity reflects the perceived powerlessness to keep control over one's job, and is likely to result in anxiety and stress, intent to leave, and decreased job satisfaction, commitment, and trust in the company. Sense of powerlessness may cause the use of aggression to regain control. A lack of procedural justice may lead to feelings of diminished control, and this sense of powerlessness makes escapist coping the more accessible option to alter the source of stress (Zellars et al. 2004). Furthermore, doctors and nurses comprise the majority of a hospital's staff and they have high training costs. Therefore, for example, understanding which antedecents influence their turnover intentions is important for hospital supervisors (Ding and Lin 2006).

The results indicate that managers must pay attention to employees' perceptions of procedural injustice. Employees who perceive that procedures are fair will be more likely to have a sense of control and lower social isolation feelings. These results support the importance of employee participation and control in decision-making processes. Managers should allow employees to provide information to the decision maker before a decision is made (Posthuma, Maertz, and Dworking 2007). In addition, an accurate and open communication environment, and regular feedback must be provided to employees by managers. According to Leiter and Maslach (2009), control is associated with fairness and reward, and helps nurses to work according to their values and to develop a healthy, sustaining worklife. Beecroft, Dorey, and Wenten (2008) also state that allowing nurses to participate in decision-making, autonomous and empowered behavior, communication, collaboration and openness in relations with other employees increased job satisfaction, improved the quality of care, and facilitated recruitment and retention.

Empowerment may be effective in overcoming the sense of powerlessness. According to Kanungo (1992), empowerment is a de-alienating strategy in feelings of powerlessness among subordinates. Brashear, Manolis, and Brooks (2005) also state that empowerment and control allows employees to be more certain of the relationship between their efforts (inputs) and outcomes such as pay or promotion. As Beecroft, Dorey, and Wenten (2008) state, empowerment is likely to cause increased job satisfaction and organizational commitment, and empowered individuals are likely to feel more control over their work. In this respect, future studies should be conducted to find out more about the relationship between procedural injustice, work alienation and empowerment. As a result of the heavy work loads of doctors and nurses, we were unable to collect a large number of surveys. Therefore, future studies should be conducted on other work environments and/or professions. [.

\section{References}

Alder, G. S. and Ambrose, M. L. 2005. Towards understanding fairness judgments associated with computer performance monitoring: An integration of the feedback, justice, and monitoring research. Human Resource Management Review 15: 43-67.

Allen, B. H. and LaFollette, W. R. 1977. Perceived Organizational Structure and Alienation Among Management Trainees. Academy of Management Journal 20 (2): 234-341.

Ambrose, M. L., Seabright, M. A., and Schminke, M. 2002. Sabotage in the workplace: The role of organizational injustice. Organizational Behavior and Human Decision Processes 89: 947-965.

Bacharach, S. B. and Aiken, M. 1979. The Impact of Alienation, Meaninglessness, and Meritocracy on Supervisor and Subordinate Satisfaction. Social Forces 57: 853-870.

Banai, M. and Reisel, W. D. 2007. The influence of supportive leadership and job characteristics on work alienation: A six-country investigation. Journal of World Business 42: 463-476.

Banai, M., Reisel, W. D., and Probst, T. M. 2004. A managerial and personal control model: perceptions of work alienation and organizational commitment in Hungary. Journal of International Management 10: 375-392.

Baron, R. M. and Kenny D. A. 1986. The moderator-mediator variable distinction in social psychological research: Conceptual strategic and statistical considerations. Journal of Personality and Social Psychology 51: 1173-1182.

Beecroft, P. C., Dorey, F., and Wenten, M. 2008. Turnover intention in new graduate nurses: a multivariate analysis. Journal of Advanced Nursing 62 (1): 41-52.

Blader, S. L. and Tyler, T. R. 2003. What constitutes fairness in work settings? A four-component model of procedural juctice. Human Resource Management Review 13: 107-126.

Boer, E. M. D., Bakker, A. B., Syroit, J. E., and Schaufeli, W. B. 2002. Unfairness at work as a predictor of absenteeism. Journal of Organizational Behavior 23: 181-197.

Brashear, T. G., Manolis, C., and Brooks, C. M. 2005. The effects of control, trust, and justice on salesperson turnover. Journal of Business Research 58: 241- 249.

Cohen-Charash, Y. and Spector, P. 2001. The role of justice in organizations: A meta-analysis. Organizational Behavior and Human Decision Processes 86: 278-232.

Colquitt, J. A. 2001. On the dimensionality of organizational justice: A construct validation of a measure, Journal of Applied Psychology 86: 386-400.

Colquitt, J. A., Scott, B. A., Judge, T. A., and Shaw, J. C. 2006. Justice and personality: Using integrative theories to derive moderators of justice effects. Organizational Behavior and Human Decision Process 100: 110127. 
Cropanzano, R., Byrne, Z. S., Bobocel, D. R., and Rupp, D. E. 2001. Moral Virtues, Fairness Heuristics, Social Entities, and Other Denizens of Organizational Justice. Journal of Vocational Behavior 58: 164-209.

Cropanzano, R., Prehar, C. A., and Chen, P. Y. 2002. Using Social Exchange Theory to Distinguish Procedural From Interactional Justice. Group and Organization Management 27: 324-351.

Dailey, R. C. and Kirk, D. J. 1992. Distributive and Procedural Justice as Antecedents of Job Dissatisfaction and Intent to Turnover. Human Relations 45 (3): 305-317.

Ding, C. G. and Lin C. P. 2006. Comparing the Effects of Determinants of Turnover Intentions Between Taiwanese and U.S. Hospital Employees. Human Resource Development Quarterly 17 (4): 403-421.

Elovainio, M., Kivimaki, M., Steen, N., and Vahtera, J. 2004. Job decision latitude, organizational justice and health: multilevel covariance structure analysis. Social Science and Medicine 58: 1659-1669.

Elovainio, M., Van den Bos, K., Linna, A., Kivimaki, M., Ala-Mursula, L., Pentti, J., and Vahtera, J. 2005. Combined effects of uncertainty and organizational justice on employee health: Testing the uncertainty management model of fairness judgments among Finnish public sector employees. Social Science and Medicine 61 (12): 2501-2512.

Enshner, E. A., Grant-Vallone, E. J., and Donaldson, S. I. 2001. Effects of Perceived Discrimination on Job Satisfaction, Organizational Commitment, Organizational Citizenship Behavior, and Grievances. Human Resource Development Quarterly 12 (1): 53-72.

Folger, R. and Konovsky, M. A. 1989. Effects of Procedural and Distributive Justice on Reactions to Pay Raise Decisions. Academy of Management Journal 32 (1): 115-130.

Greenberg, J. 1990. Organizational Justice: Yesterday, Today and Tomorrow. Journal of Management 16: 399-432.

Greenberg, J. 2001. Setting the Justice Agenda: Seven Unanswered Questions about What, Why, and How. Journal of Vocational Behavior 58: 210-219.

Greenberg, J. 2004. Stress Fairness to Fare No Stress: Managing Workplace Stress by Promoting Organizational Justice. Organizational Dynamics 33 (4): 352-365.

Greenberg, J. 2006. Losing Sleep Over Organizational Injustice: Attenuating Insomniac Reactions to Underpayment Inequity With Supervisory Training in Interactional Justice. Journal of Applied Psychology 91 (1): 58-69.

Greenberg, J. and Barling, J. 1999. Predicting employee aggression against coworkers, subordinates and supervisors: the roles of person behaviors and perceived workplace factors. Journal of Organizational Behavior 20: 897-913.

Hegtvedt, K. A., Clay-Warner, J., and Johnson, C. 2003. The Social Context of Responses to Injustice: Considering the Indirect and Direct Effects of Group-Level Factors. Social Justice Research 16 (4): 343-367.

Heinz, W. R. 1991. Changes in the methodology of Alienation Research. The International Journal of Sociology and Social Policy 11 (68): 213.

House, R. and Rizzo, J. 1972. Role conflict and ambiguity as critical variables in a model of organizational behavior. Organizational Behavior and Human Performance 7: 467-505.

Hubbel, A. P. and Chory-Assad, R. M. 2005. Motivating Factors: Perceptions of Justice and Their Relationship with Managerial and Organizational Trust. Communication Studies 56 (1): 47-70.

Jamal, M. 2005. Short communication: Personal and organizational outcomes related to job stress and Type-A behavior: A study of Canadian and Chinese employees. Stress and Health 21: 129-137.

Judge, T. A. and Colquitt, J. A. 2004. Organizational Justice and Stress: The Mediating Role of Work-Family Conflict, Journal of Applied Psychology 89 (3): 395-404.
Kanungo, R. N. 1983. Work Alienation: A Pancultural Perspective. International Studies of Management and Organization 13: 119-138.

Kanungo, R. N. 1992. Alienation and Empowerment: Some Ethical Imperatives in Business. Journal of Business Ethics 11: 413-422.

Kickul, J., Gundry, L. K., and Posig, M. 2005. Does Trust Matter? The Relationship Between Equity Sensitivity and Perceived Organizational Justice. Journal of Business Ethics 56: 205-218.

Konovsky, M. A. 2000. Understanding Procedural Justice and Its Impact on Business Organizations. Journal of Management 26: 489-511.

Krehbiel, P. J. and Cropanzano, R. 2000. Procedural Justice, Outcome Favorability and Emotion. Social Justice Research 13: 339-360.

Lam S. S. K., Schaubroeck, J., and Aryee, S. 2002. Relationship between organizational justice and employee work outcomes: a cross-national study. Journal of Organizational Behavior 23: 1-18.

Leiter, J. 1985. Work Alienation in the Textile Industry: Reassessing Blauner. Work and Occupations 12: 479-498.

Leiter, M. P. and Maslach, C. 2009. Nurse turnover: the mediating role of burnout. Journal of Nursing Management 17: 331-339.

Mendoza M. J. S. and Lara, P. Z. M. 2007. The impact of work alienation on organizational citizenship behavior in the Canary Islands. International Journal of Organizational Analysis 15 (1): 56-76.

Miller, J. 1975. Isolation in Organizations: Alienation from Authority, Control, and Expressive Relations. Administrative Science Quarterly 20: 260-271.

Nasurdin, A. M., Ramayah, T., and Kumaresan, S. 2005. Organizational Stressors and Job Stress among Managers: The Moderating Role of Neuroticism. Singapore Management Review 27 (2): 63-79.

Nowakowski, J. M. and Conlon, D. E. 2005. Organizational Justice: Looking Back, Looking Forward. The International Journal of Conflict Management 16 (1): 4-29.

Posthuma, R. A., Maertz, C. P., and Dworkin, J. B. 2007. Procedural justice's relationship with turnover: Explaining past inconsistent findings. Journal of Organizational Behavior 28: 381-398.

Price, K. H., Lavelle, J. J., Henley, A. B., Cocchiara, F. K., and Buchanan, F. R. 2006. Judging the fairness of voice-based participation across multiple and interrelated stages of decision making. Organizational Behavior and Human Decision Processes 99: 212-226.

Robbins, T. L., Summers, T. P., and Miller, J. L. 2000. Intra- and interjustice relationships: Assessing the direction. Human Relations 53 (10): 1329-1355.

Sarros, J. C., Tanewski, G. A., Winter, R. P., Santora, J. C., and Densten, I. L. 2002. Work Alienation and Organizational Leadership. British Journal of Management 13: 285-304.

Schmitt, M. and Dörfel, M. 1999. Procedural injustice at work, justice sensitivity, job satisfaction and psychosomatic well-being. European Journal of Social Psychology 29: 443-453.

Shepard, J. M. 1970. Functional Specialization: Alienation, and Job Satisfaction. Industrial and Labor Relations Review 23 (2): 207-219.

Sipahi, B., Yurtkoru, E. S., and Cinko, M. 2008. Data Analysis with SPSS in Social Sciences. 2nd ed., Istanbul, ISBN 978-975-295-827-2.

Tabak, N. and Koprak, O. 2007. Relationship between how nurses resolve their conflicts with doctors, their stress and job satisfaction. Journal of Nursing Management 15: 321-331.

Taylor, S., White, B., and Muncer, S. 1999. Nurses' cognitive structural models of work-based stress. Journal of Advanced Nursing 29 (4): 974983.

Tepper, B. J. 2001. Health Consequences of Organizational Injustice: Tests of Main and Interactive Effects. Organizational Behavior and Human Decision Processes 86: 197-215.

VanYperen, N. W., Hagedoorn, M., Zweers, M. and Postma, S. 2000. Injustice and Employees' Destructive Responses: The Mediating Role of State Negative Affect. Social Justice Research 13 (3): 291-312. 
Vermunt, R. and Steensma, H. 2003. Physiological Relaxation: Stress Reduction Through Fair Treatment. Social Justice Research 16 (2): 135 149.

Yang, M. J., Yang, M. S., and Kawachi, I. 2001. Work experience and drinking behavior: alienation, occupational status, workplace drinking subculture and problem drinking. Public Health 115: 265-271.

Zellars, K. L., Liu, Y., Bratton, V., Brymer, R., and Perrewe, P. L. 2004. An Examination of the Dysfunctional Consequences of Organizational Injustice and Escapist Coping. Journal of Managerial Issues 16 (4): 528-

545. 